\title{
ABSTRACT \\ EVALUATING THE EXPERIENCE OF PATIENT AND PROVIDER SATISFACION IN PARTICIPATION IN A HYBRID VIRTUAL PERINATAL CARE MODEL IN A PRIVATE PRACTICE SETTING
}

Improving access to health care in general and to appropriate prenatal care specifically are two leading health indicators (LHI) as designated by Healthy People 2020 (U.S Department of Health and Human Services, 2010). The California Department of Public Health (CDPH) also prioritizes minimizing health disparities that prevent women from entering into prenatal health care (CDPH, 2019). In Fresno county, transportation to specialty care such as perinatal care has been identified as a barrier (CDPH, 2017). The American College of Obstetricians and Gynecologists (ACOG) and The American Academy of Pediatricians (AAP) have identified a standard of fourteen to sixteen visits for routine perinatal care (Riley, Papile, \& Kilpatrick, 2012) which has demonstrated best outcomes for mother and baby. These visits can result in disruption of work, increased child care expenses, travel and long office wait times that can lead to barriers to participation in adequate perinatal care. This doctoral project will be a pilot study to evaluate patient satisfaction with participation in this model as the virtual component is a new addition to standard office care. The project will also evaluate physician and nurse practitioner (NP) satisfaction in providing virtual obstetric care in order to help determine if this novel model can help decrease obstacles to care.

Keywords: perinatal care, virtual care, telehealth

Abstract Gretchen A Nelson April 2020 



\title{
EVALUATING THE EXPERIENCE OF PATIENT AND PROVIDER SATISFACTION IN PARTICIPATION IN A HYBRID VIRTUAL PERINATAL CARE MODEL IN A PRIVATE PRACTICE SETTING
}

\author{
by \\ Gretchen Ann DeLong Nelson
}

\author{
April 2020 \\ A project \\ submitted in partial \\ fulfillment of the requirements for the degree of \\ Doctor of Nursing Practice \\ California State University, Northern Consortium \\ Doctor of Nursing Practice
}




\section{APPROVED \\ For the California State University, Northern Consortium Doctor of Nursing Practice:}

We, the undersigned, certify that the project of the following student meets the required standards of scholarship, format, and style of the university and the student's graduate degree program for the awarding of the master's degree.

$\frac{\text { Gretchen Ann DeLong Nelson }}{\text { Project Author }}$

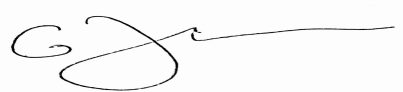

April 20, 2020

Carrie Holschuh (Chair)

Nursing

Gretchen Ezaki

Nursing

Adanna Ikedilo

Obstetrician Gynecologist 


\section{AUTHORIZATION FOR REPRODUCTION}

\section{OF DOCTORAL PROJECT}

$\underline{\mathrm{X}} \quad$ I grant permission for the reproduction of this project in part or in its entirety without further authorization from me, on the condition that the person or agency requesting reproduction absorbs the cost and provides proper acknowledgment of authorship.

Permission to reproduce this project in part or in its entirety must be obtained from me.

Signature of project author: $\quad$ Geterma Nelson 4/22/2020 


\section{ACKNOWLEDGMENTS}

I would like to thank and acknowledge the following people without whom I would never have gotten through this journey.

First, my project chair: Dr. Carrie Holschuh. Your patience, intelligence and encouragement have been truly inspiring. It has truly been a privilege to have worked with you.

My Husband David has been my chief cheerleader and advocate throughout these three years. He deserves a $\mathrm{PhD}$ in support services and encouragement. My sons Charles and Kenneth have provided fresh insight when I needed it. My niece

Jen DeLong who has been a role model as women who demonstrates leadership in the world of technology.

Dr. Gretchen Ezaki, committee member, who put a match under my feet to start this process and has kept the fire going ever since.

Dr. Adanna Ikedilo, committee member, who was willing to step in early on and help me investigate new avenues in perinatal care.

Dr. Stewart Mason for getting the telehealth program going and kept pushing to keep it on track.

My advisor Dr. Lisa Walker-Vischer who has always responded quickly to my anxieties and provided positive support every step of the way.

My telehealth mentors: Maureen Faccia, MBA, Melinda Carlie, NP, Amber Hoffman, NP and Bethann Pfugeisen who all were willing to answer a stranger's call or email and took time out of their lives to share their knowledge.

Debra Neufeld whose patience and skill in helping me put this project together was a life saver. 
TABLE OF CONTENTS

Page

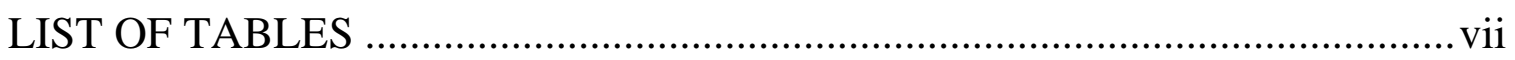

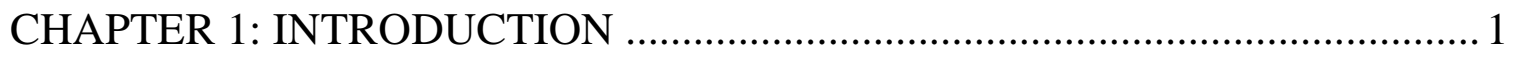

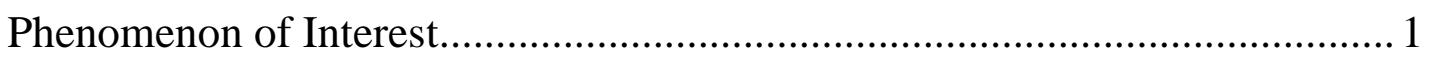

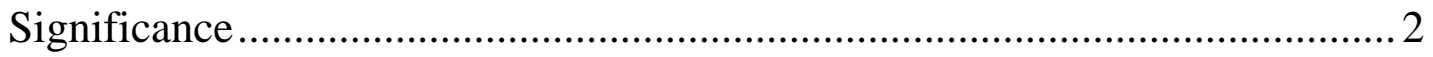

Theoretical Framework Imogene King's Theory of Mutual Goal Attainment: Origins............................................................................... 4

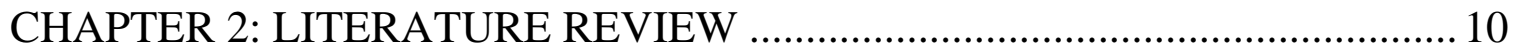

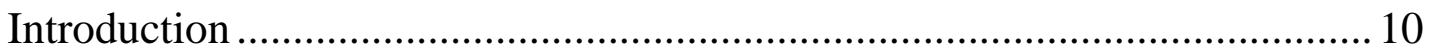

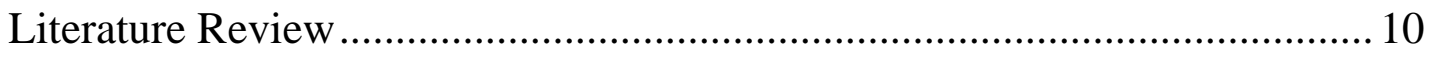

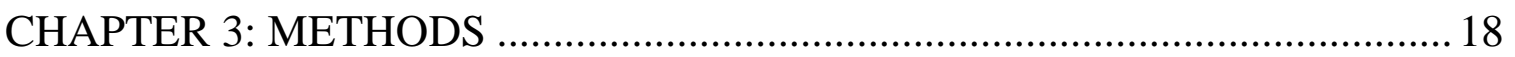

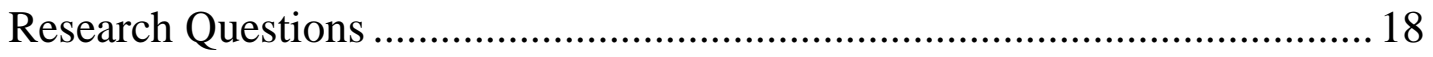

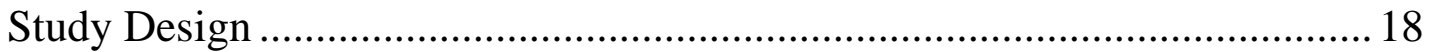

Setting and Sample Characteristics ................................................................. 20

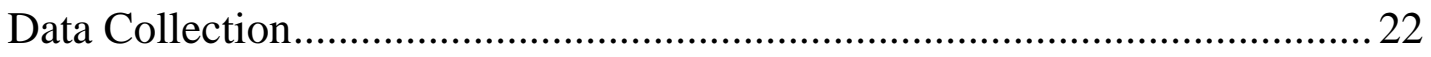

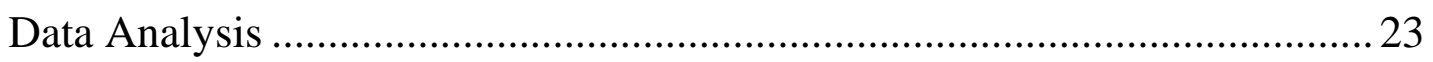

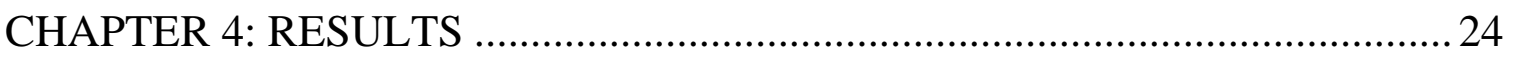

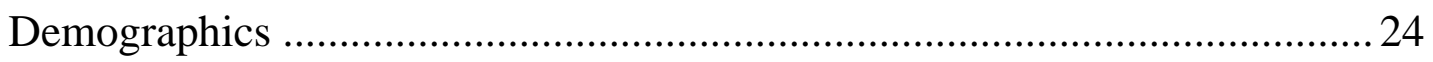

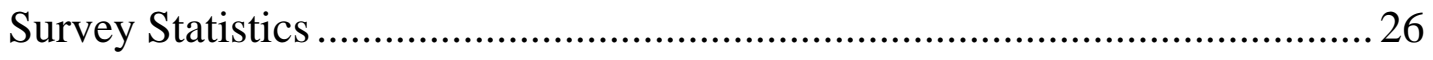

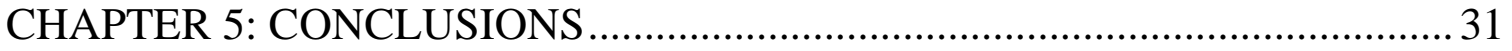

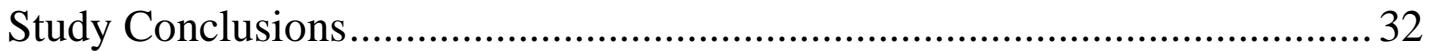

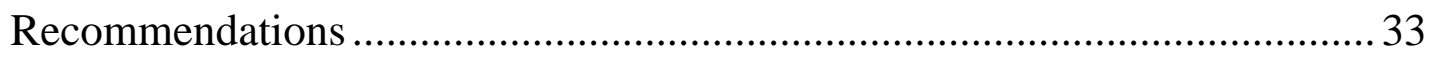

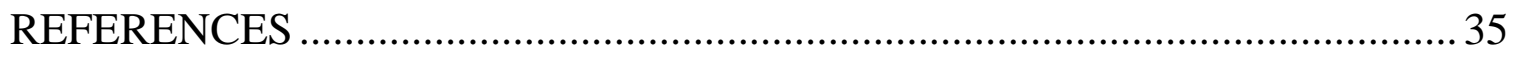

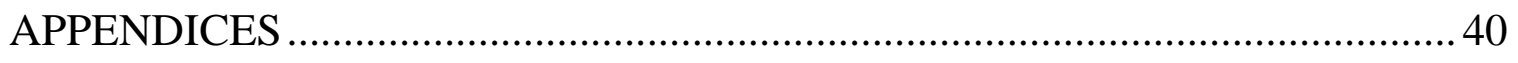

APPENDIX A: MULTICARE PERMISSION TO USE SURVEY …................... 41 
APPENDIX B: PERMISSION TO USE SURVEY ........................................ 43

APPENDIX C: PATIENT SURVEY ......................................................... 46

APPENDIX D: PROVIDER SURVEY .................................................... 56 


\section{LIST OF TABLES}

Page

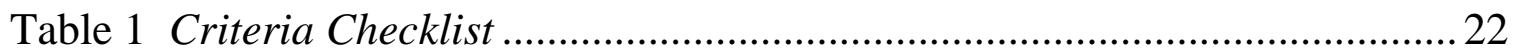

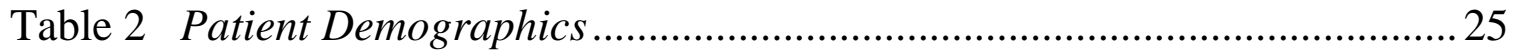

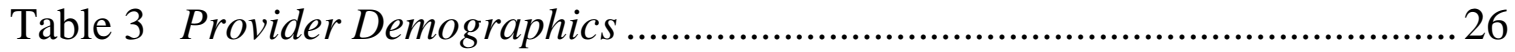

Table 4 Descriptive Results for Means < 4.3 ...................................................... 27

Table 5 Paired Samples Correlations for Patient Experience ……....................... 28

Table 6 Paired Sample T Tests for Significant Results of Virtual to Office......... 29

Table 7 One-way ANOVA for Overall Patient Experience and Income ............... 29 


\section{CHAPTER 1: INTRODUCTION}

\section{Phenomenon of Interest}

The beneficial outcomes of consistent prenatal care starting early in pregnancy have been extensively studied and accepted as a means to improve the wellbeing of both mother and infant. In the United States, the American College of Obstetricians and Gynecologists (ACOG) suggests a model of prenatal care visits that is traditionally done in an office setting (Riley, 2012). Group prenatal care is a newer model of perinatal care which follows the same schedule of visits, however most of the care occurs in a group setting with one or two providers present. The group model has demonstrated similar outcomes to the traditional model, with the benefit of improved patient satisfaction for some women and lower cost to insurers (Cunningham et al., 2019). Women in group care are taught to take their own blood pressure, weigh themselves and dip their urine for protein and glucose each visit. Augmenting this model with an integrated HIPAA-secure patient portal to access electronic medical records and to provide patients the ability to contact their medical providers, while still maintaining the group design, has shown additional improvements in perinatal outcomes, patient satisfaction and health care costs (Cunningham, Lewis, Thomas, Grilo, \& Ickovics, 2017).

Both the traditional and group models of perinatal care require the attendance of pregnant women to an assigned location for every prenatal visit. Barriers to accessing care for women can include: time and cost of travel, loss of wages to attend appointments, and difficulty finding child care to attend appointments. The newest model of perinatal care follows the traditional model of scheduled visits; however, it incorporates virtual visits into the schedule 
(Pflugeisen, McCarren, Poore, Carlile, \& Schroeder, 2016). This model has bridged the gap from exclusive attendance at a brick and mortar location to appointments that accommodate pregnant women's need for flexibility. This hybrid model has also been shown to maintain patient satisfaction in one study (Pflugeisen \& Mou, 2017). No study has looked at the integration of the alternative model of a hybrid virtual perinatal care in a private practice nor has provider acceptance of this model in private practice been studied which may contribute to the rarity of this model in the greater obstetric community.

This project aims to remove the roadblocks to virtual perinatal care by assessing the concerns of medical providers, obstetricians and nurse practitioners, in a private practice setting during the initial phase of incorporating this model of care into routine care. It also will assess women's experiences of participating in a hybrid virtual obstetrics program to determine satisfaction. A hybrid program for perinatal care developed by MultiCare Health System in the state of Washington will be the model for the virtual schedule of appointments (see Appendix A). Written permission has been received from the administrator of the model to use its framework as well as the patient satisfaction tool (Appendix B) for its use during the project. The model will be used by the obstetric care providers such as doctors, certified nurse midwives and nurse practitioners. A survey to evaluate patient satisfaction (see Appendix C) and a survey to evaluate provider satisfaction with virtual obstetric practice (see Appendix D) will be the tools used in the project.

\section{Significance}

Prenatal care has consistently been shown to improve perinatal outcomes. Preterm delivery ( $<37$ weeks of gestation) decreases significantly in women who 
participate in perinatal care, particularly in the first trimester of pregnancy (Shapiro-Mendoza et al., 2016). Maternal outcomes also improve with initiation of prenatal care. Postpartum depression, pregnancy related hypertension and maternal death in the United States all show improved outcomes with quality prenatal care (Wong \& Kitsantas, 2019).

Healthy People 2020 determines the leading health indicators (LHI) of high concern for the US population and addresses strategies for improvement (2010). Access to health services is listed as the first objective. Barriers to care identified include geographical availability of needed services and cost of care to the patient. The associated costs for participation in prenatal care is more than just the actual financial payment for each visit such as health insurance deductibles and co-pays. Cost also includes lost wages and potential childcare costs to attend appointments. Healthy People 2020's LHI for Maternal Infant and Child Health (MICH) Objective 9.1 is to decrease preterm deliveries and Objective MICH 10.2 is to increase early and adequate access to prenatal care (2010). Given that accessing care and obtaining prenatal care are high priority objectives, involvement in a new means to provide quality and accessible prenatal care must also be a priority. Barriers need to be removed by embracing new models to incorporate alternative care options to fit the needs of every woman. Not only does decreasing obstacles to prenatal care improve overall access, it also provides a means to empower women with choices regarding the type of care that fits best into their life. Attendance to appointments is not limited to distance from appointments, or residence in rural and remote locations. Access to care can be problematic for women who live and work in a continuum of environments that pose many obstacles to each individual. Allowing each woman to decide what type of care fits best for their needs encourages should improve consistency of care. 


\section{Theoretical Framework Imogene King's Theory of Mutual Goal Attainment: Origins}

Imogene King's theory of goal attainment was first published in 1981, however she began developing her conceptual framework in the 1960s. During the early development of her theory, she investigated trends in healthcare while planning curriculum for a master of nursing program at Loyola University in Chicago, Illinois (Houser \& Player, 2007); (Sieloff Evans, 1991). She based her conceptual framework on the systems theory of Ludwig von Bertalanffy (Sieloff Evans, 1991). Bertalanffy's theory concluded that the entirety of a system is not as simple as adding the pieces of its parts together and that there is a net difference of increased complexity when all the pieces come together (Bertalanffy, 1968). When King applied this systems theory to the practice of nursing, she looked at humans as both individuals and as members of groups. A human has many "pieces" such as psychological, spiritual or physical. A group or community is made up of individual persons who are multifaceted. Whether looking at a human as an individual or as part of a community, there is a difference of increased complexity of the whole being or whole community as opposed to when examining each piece of the being or member of the group (Whetsell, 2018). As King was developing her theory in the 1960s, she also looked at the trends in society that affected health care. She particularly addressed the nursing community as an integral member of the healthcare system. The trends she identified are: "knowledge explosion, technological advances, constant changes in population composition and the mobility of the workforce" (Sieloff Evans, 1991). In Sieloff Evans' book on King's conceptual framework, she commented that these trends continued to be current in 1991 (Sieloff Evans, 1991). King's assessments demonstrated forward thinking and a desire to apply nursing activities to current society regardless of the era. Her theory incorporates the assumption that technology and population 
response to technology is always advancing and needs to be addressed by nursing and health care. She also comments on the composition of populations as they evolve and change over time. These forward-thinking assumptions make her work as viable in 2019 as it was fifty years ago. In her early work, King identified nurses as, "key persons in the health care systems" and therefore essential to the system as a whole (Sieloff Evans, 1991). Again, the usefulness of her implication that nursing is not a separate entity but vital to the whole of health care is important when addressing the needs of a patient with a medical condition that requires advanced practice nursing interventions.

\section{Assumptions, Concepts and Testing of King's Theory}

As her theory progressed over time from 1968 to 1981, King's theory of goal attainment was finalized. There would be revisions over time, however the main concepts and assumptions were formed by 1981. The theory's foundation is the framework containing four defining elements. First there is her concept of structure which is the person interacting in the environment. Next, she defines multiple nursing functions which can occur simultaneously. Resources both human and material are determined. Finally, a goal is determined based in health care (Sieloff Evans, 1991). Key to her theory are the concepts of a personal system, an interpersonal system and a social system which interact together and lead to transactions for mutual goal attainment (King, 1991; Whetsell, 2018). The assumptions for nurse-client interaction presented in her 1981 book are: (1) Perceptions of the nurse and of the client influence the interaction process; (2) Goals, needs and values of nurse and client influence the interaction process; (3) Individuals have a right to knowledge about themselves; (4) Individuals have a right to participate in decisions that influence their life, their health, and 
community services; (5) Health professionals have a responsibility to share information that helps individuals make informed decisions about their health care; (6) Individuals have a right to accept or reject health care; (7) Goals of health professionals and goals of recipients of health care may be incongruent (King, 1981).

As King refined her conceptual model and developed the theory, she concluded that the focus should be on the interpersonal system between nurse and client when they work together to "maintain a state of health that permits functioning in roles" (King, 1981, p.142). She further developed multiple concepts for goal attainment, but for the purpose of this project three will be highlighted for the nurse client system: interaction, perception and transaction. Interaction is mutual interdependence needed to achieve goals (King, 1981, p.84). Perception refers to each individual's sense of a situation and health, and is dependent on the individual's knowledge, and experiences (King, 1981, p.120), which requires both nurse and client to use their insights to interact together in a meaningful way. Finally, transaction requires interaction which she states is, "a series of events in time used to achieve a goal" (King, 1981, pp.80-81) (Sieloff Evans, 1991).

In reviewing the literature, there are multiple cases in which King's theory has been applied to research and tested. In fact, King herself created a means to test her theory to validate its reliability to "demonstrate a way for nurses to interact purposefully with clients," particularly with nursing documentation (King, 1991). She also applied it in the use of curriculum development (Sieloff Evans, 1991).

\section{Application and Relevance of King's Theory to Prenatal Care}

King's middle range systems theory titled, "Theory of Goal Attainment" is relevant in clinical-based settings as it emphasizes the use of a systems science 
approach which can facilitate interdisciplinary coordination (Lenz, 1998). King's theory of goal attainment uses both the conceptual framework of a systems theory and the middle range theory to address individual and group needs which is useful in the clinical practice setting (Sieloff Evans, 1991). Mutual goal setting is necessary for women to participate in perinatal care. Usually the health care setting, environment and provider dictate to the pregnant woman in regards to where and how appointments for care will occur. Using mutual goal setting between the woman client and the health care provider should include the client's participation in goal setting. There must be options in this care, or there is no opportunity for mutually agreed upon goals and the potential for successful interaction to achieve the goal attainment resulting in the optimal health possible for mother and infant.

The need for mutual goal setting in the application of King's theory requires nurse-client interaction, perception and transaction among other relationship dynamics. Women who are stressed and pressed for time due to work and family demands may not follow through with prenatal care if the appointments are not conducive to allowing them to meet the demands of their individual lives. This doctoral project goal is to increase access through using telehealth technology to make appointments more available and require less time away from work and family which in turn may decrease loss of wages and income. With the possibility of increased accessibility, the goals of maintaining health and promoting wellbeing for the woman, the growing fetus, as well as her family can be met and result in a potential improvement in birth outcomes. Improving access with the use of virtual obstetric care will also empower the woman to participate in this care. As King's theory indicates, the client has the right to accept or reject healthcare. Improving access will hopefully improve the acceptance of the requirements of 
perinatal care, resulting in a successful transaction between the client and the advanced practice registered nurse.

The brick and mortar medical office buildings are still necessary for most prenatal care at this time. However, not all medical care necessitates face-to-face appointments with client and provider. Electronic medical records (EMR) are available to allow for access to patient records outside of the office. Interface between the provider and the client using applications available by smart phone or computer while accessing an EMR system provides access to care. There is no loss of data. The virtual obstetric appointment and education can be done using the telehealth technology on the device available to the client. As Imogene King stated in the 1960s, technological changes are a driving force of healthcare. Telehealth, like EMR systems, are two means to improve patient access to care using technology which result in the mutual interaction and transaction between provider and client.

In addition to using technology to improve patient access, another aspect to consider with the application of virtual obstetric care in the provider client interaction is in the respect of time as a function of access to care. Travel time and office wait times can and do discourage patient participation in prenatal care. Using technology such as a mobile phone can enhance mutual accommodation of availability of both provider and the patient. If one is running behind for an appointment, to notify the provider and adjust the virtual appointment can be arranged quickly. If either party is running behind or even ahead of schedule, waiting in a waiting room or complete cancelation may be prevented. A patient who is ill or caring for an ill child may be able to attend a virtual appointment at home and not miss an appointment or risk exposing other patients to illness. Thus, the meaningful mutual transaction required for healthcare is obtained. For King's 
conceptual framework and her theory, interaction needs to be mutual (King, 1981). If only the provider's schedule is the priority, then the patient is made to wait in a waiting room unnecessarily. If only the patient is the priority, then the provider will get behind or have unfilled appointment times if the patient cannot physically get to her appointment. Adjustments in the schedule do require an agreement to meet the goal of maintaining appointments regardless if they are face to face in an office or virtual via telehealth. Adding the increased flexibility to meet virtually improves the goal of participating in scheduled perinatal care and the outcome of maintaining maternal, baby and family wellbeing. The concept of power which King defines as the, "capacity to use resources in organizations to achieve goals" is then achieved (King, 1981).

Most patients in the childbearing age group have a smartphone or computer. It will be necessary to create a structure for the model of care so that the network interaction between provider and the patient is accessible and creates a means to satisfy both the patient's and provider's needs so the transaction continues to be mutual.

King's model is proactive and a positive theoretical structure for the type of care model that can serve the perinatal patient. The model can be used to create a structure which could consistently address the mutual interaction, transaction and goal setting that would benefit accessing care for these women. It is not a hierarchical focused model where the provider is the authority who dictates time, place and even health goals, but a theory that can empower both patient and provider to work toward the mutual goal attainment in quality obstetrical care. 


\section{CHAPTER 2: LITERATURE REVIEW}

\section{Introduction}

Telehealth is often discussed as an emerging means of providing health care which is evolving in its outreach into many disciplines and service areas. However, it has been around in some form for several decades. The literature is deep in publications and research studies in its use. From neonatology to end of life care, it is possible to find something published on the use of telehealth as an adjunct or primary source of care. Telehealth is no longer novel as an entity (Roth, 2018), however there continue to remain sceptics in its utility particularly in the spectrum of obstetric care. As will be demonstrated in the literature review, virtual obstetric care does exist in a few settings with very limited information regarding patient and provider satisfaction in a private practice. This doctoral project aims to evaluate the satisfaction in the joint participation of receiving and providing perinatal care. It also will highlight the improvements in access to perinatal care that a hybrid virtual obstetric model has to offer. Hopefully, it will also plant the seeds that the demographics of patients who are able and willing to participate in nontraditional care are wide and it will result in favorable outcomes.

\section{Literature Review}

In order to evaluate pregnant women's satisfaction in care, it is integral to explore the barriers to perinatal care. Phillipi looked at 10 years' worth of literature investigating women's perceived barriers to care from 1999 to 2009. This time frame sets up the foundation of the current era of telehealth and why access interferes with women's engagement in prenatal care. The author ends with the statement: "a focus in future research on facilitators of access can assist in creating open pathways to perinatal care for all women" (Phillippi, 2009). Using 
these words as an impetus for this doctoral project, a satisfying means to improve access needs to be continually investigated.

Pflugeisen, McCarren, Poore, Carlile and Schroeder (Pflugeisen et al., 2016) compared low risk pregnant women who elected to participate in a traditional model of prenatal care with those who elected to participate in a model that included virtual visits. Characteristics of demographics as well as birth outcome were also assessed. The goal of the study was to determine if there is increased risk associated with the new model and if a difference in demographics for the women who chose the virtual model exists. It was a retrospective study that used data extraction from the electronic medical record (EMR) from one health care system in Washington state from May 2011 to December 2013. A total of 1,058 were enrolled in the OB health care system, with 941 in traditional care and 117 in the virtual component. Data analysis for demographics used a predictive logistic model to identify significant factors. Birth outcome data was evaluated with logistic regression for binary outcomes and ANCOVA.

Significant results for demographics were women who selected the virtual component were twice as likely to have a partner, were seven times more likely to have had previously given birth before and were less likely to be enrolled in a supplemental food assistance program. Birth outcomes indicated that there was no increase in mean birth weight, gestational age at delivery or neonatal intensive care units (NICU) admissions. Maternal outcomes were similar. No increase in gestational diabetes or cesarean delivery were noted however there was a small but significant increase in preeclampsia for those that selected virtual care $\mathrm{p}=0.02$. A strength of this study is that it had the records for all its participants throughout their prenatal care so loss to follow up was not a problem. A limitation of the study was selection bias. All the participating pregnant women in the study were 
enrolled in the same health care system with multiple providers under one umbrella organization. They also had access to a standard of comprehensive primary health care that was established prior to pregnancy. An interesting demographic is that the traditional care group's average age at enrollment was 29 (age range of 23.7 to 34.5 years) and those that selected the virtual option age was 30.3 (age range of 25 years to 34.8 years). This is a fairly close age range for all participants and may not represent the greater population as a whole.

The opportunity to participate in virtual care does not necessarily indicate patient satisfaction with the care provided. Quality care encompasses patient satisfaction as well. A follow up study to the virtual care study was conducted by Pflugeisen \& Mou (Pflugeisen \& Mou, 2017) to assess satisfaction in virtual perinatal care from March 2013 to January 2016. Women were allowed to selfselect to participate in virtual care. A total of 430 women participated in virtual care and 860 traditional-care women were mailed satisfaction surveys using a Likert scale. 75 patients who selected virtual care and 96 traditional care patients responded. Multiple domains within the questionnaire evaluated aspects of patient satisfaction such as: overall, provider, personal and schedule using analysis of variance (ANOVA). Virtual-care patients highly favored overall satisfaction more than traditional care patients. The responders were cross matched by ethnicity and income. The virtual-care patients were more likely to have already had one successful pregnancy outcome (baby) prior to participating in virtual care. The advantage of the study was that it did survey multiple domains of satisfaction. A drawback in the results was that parity was not matched in the participants. Women who had not previously had a positive pregnancy outcome or were primigravida may be more reluctant to self-select out of traditional care and may have less scheduling challenges than those with children. 
Other research in patient satisfaction for participation in telehealth supports Pflugeisen \& Mou's findings particularly for women. A study that looked at patient preferences for care comparing traditional and telehealth visits indicated that $94 \%$ of the 3303 patients surveyed reported being very satisfied with telehealth visits. Female patients were predictably the most satisfaction in participation of telehealth care ( $\mathrm{OR}=1.68)$ (Polinski et al., 2016). Although this study was not specific to perinatal care, it does address patient satisfaction in relation to perceived quality of care and did address patient access to care as data points to be evaluated. Both of which were rated very high by participants.

A study in Arkansas was able to demonstrate improved outcomes even with high risk populations. The Antenatal and Neonatal Guidelines, Education and Learning System (ANGELS) is a model which has been used in high-risk obstetric care (Bronstein et al., 2012). This model utilized telehealth for specialty obstetric and neonatal care in rural Arkansas. A retrospective study used birth certificates and EMR coding to evaluate the type of specialty telehealth care which was accessed such as ultrasound or maternal fetal medicine evaluations specialists' consults. The results indicated that women who saw an OB/GYNs in the remote setting were more likely to have telehealth consults as compared to those who were being followed by their primary care providers. The demographic and diversity data showed mixed results in that Black women, unmarried women and those with minimal education were less likely to have access to telehealth specialty referrals. In this case, telehealth access was demonstrated to be limited to certain groups. An important value of this study is that it helped to identify groups who were possibly not selected for telehealth visits by their local providers due to discrimination, perhaps not intentional discrimination, but nonetheless unequal standards were identified as barriers to telehealth. As the study was a retrospective 
study, it had a potential to miss patients who moved out of the area prior to delivery such as migrant workers who did not deliver where they received care.

The ethical concept of justice is important to consider when discussing access to care particularly for underserved populations and those that may be deemed as having limited health literacy. Accessing care should not translate to inferior care, or care that assumes the patient is unable to fully participate. Care that is available to the greater population regardless of individual circumstance should be offered to all appropriate people. A study using telehealth in perinatal depression addressed the use of telehealth in an underserved population. It looked specifically at Latina women (Baker-Ericzén et al., 2012) as means to assess feasibility of behavioral health care in collaboration with other healthcare professionals. This study randomly selected a cohort of 79 women from a larger study that assessed Mexican-American mothers with major depression. All were pregnant or within 6 weeks post-delivery. Via this county program, they were identified as having major depression. They were given phone psychotherapy lasting from 14-47 minutes. A survey was conducted one month after the end of the phone psychotherapy. 97\% of these women indicated the intervention was helpful, 91\% stated it provided all the assistance they needed and 94\% indicated that the mental health provider understood their situation. This study shows that telehealth can be used in a variety of settings with basic phone technology. It identified a specific population who may not have otherwise received mental health care or been offered the option of telehealth and demonstrated acceptance and satisfaction of care. Since this was part of a larger group, a comparison control group would have provided more robust data when discussing feasibility.

A small study of 41 patients and RNs used qualitative data with focus groups to look at patient satisfaction as well as $\mathrm{RN}$ job satisfaction in providing 
limited virtual obstetric care (Baron et al., 2018). None of the RNs were advanced practice nurses. The RNs were allowed to provide care to the highest level of their scope of practice and they were allowed a greater level of autonomy than they normally experienced. Both nurses and patients were found to have a level of satisfaction in the experience as least as good as a traditional visit. The value of a qualitative study is that it did allow for open dialogue between RNs and patients in sharing their experiences. This study provided minimal amount of patient or RN demographic information or information regarding inclusion information for low risk designation.

In order for an obstetric provider to consider initiating telehealth in perinatal care, understanding the needs of stakeholders is necessary. A comprehensive study evaluated leaders in medical systems to determine who and why they are directing their organizations towards or away from telehealth (Brown Cooper, 2015). The focus was on opinion leaders, such as CEOs, in their institutions. Using a diffusion of innovations theory (Rogers, 2003), interviews, non-participant observations and documentation review were applied to a crosscase analysis and compared to a normative group. A small increase in adoption of innovative telehealth programs was determined to result if the identified opinion leaders were involved in the decision making. This study was pertinent in that evaluating who will make decisions regarding use of technology and innovation ultimately must be approved by the top of an organization. The disadvantage of the study is it appeared to depend on observer evaluation over time which could be biased by inter rater reliability and this was not accounted for in the study. 


\section{Gaps in the Literature}

The benefits of perinatal care are universally accepted and well documented in the literature. The use of telehealth in all settings is growing in acceptance across disciplines and populations. In doing research for this doctoral project, the literature review shows two large gaps. The first is evaluation of patient satisfaction for those who elect to participate in a hybrid model of perinatal care in a private practice. Pflugeisen's study of comparing group satisfaction between those who only participated in traditional care versus those who participated in virtual care demonstrated more satisfaction in the group who participated in the virtual hybrid model (Pflugeisen \& Mou, 2017). The study did look at demographic differences between these two groups to help identify types of patients more likely to choose one model over the other. However, to understand the nuances of the visits and to better understand where satisfaction lies, it would be of value to ascertain if the option for choice is what provided satisfaction or the type of visit. A sub component of this study is that all patients participating were part of the same health network, MultiCare. Another gap is in evaluating provider desire to initiate, engage in and acceptance for, telehealth in their office-based obstetric practices meaning the concept of obstetrical provider "buy in" to include virtual obstetric visits as part of a hybrid model. No research was found that identified obstetrical care provider's satisfaction or interest in providing virtual or telehealth care in a private office setting. If increasing access to care for perinatal women is deemed as a priority in the United States and providers are uncomfortable or reluctant to provide options in care that can extend beyond an exam room, then access to care will continue to be limited. In addition to identifying these provider concerns, this doctoral project also provides the 
opportunity to open the dialogue to increase awareness that women desire options for care. 


\section{CHAPTER 3: METHODS}

\section{Research Questions}

The purpose of this project is to evaluate satisfaction in participating in a hybrid virtual perinatal care model from both the patient and the provider experience as compared to traditional in office visits. Improving access to perinatal care using an innovative model requires that both patient and provider have confidence that the experience will be satisfying and equivalent in quality of

care. The goal is to compare the rating of at least one virtual care experience with one traditional care experience for patients and obstetrical care providers and look at factors associated with satisfaction ratings to help determine if the model can become sustainable. For women receiving routine perinatal care, does participating in at least one telehealth (virtual) visit for routine care in place of a traditional office visit, improve satisfaction in their obstetrical care experience? For medical obstetrical care providers, does participation in virtual care affect satisfaction in delivering perinatal care?

\section{Study Design}

This pilot project evaluated a cohort of pregnant women receiving perinatal care as well as a cohort of OB/GYN physician and nurse practitioner care providers which retrospectively looked at each cohort's satisfaction of experience in participation in a hybrid virtual care model. The independent variable for each cohort was the visit type, either virtual or traditional care. Comparison of satisfaction was unique to each individual. Patient satisfaction for receiving care with virtual visits was compared to the results for satisfaction of the care experience with traditional visits. Providers were likewise surveyed specific to satisfaction of the experience of providing care for each setting. The goal was to 
get between 15 to 20 patients and 7 providers. There was no compensation for participation in the project. The IRB was approved by the California State University, Fresno review board.

The patient surveys used a 5-point Likert scale measuring ordinal data for patient satisfaction using: very good, good, fair, poor or very poor to rank their experience for each type of visit. The patient survey titled, "Prenatal care patient satisfaction survey" will evaluate traditional care and virtual care appointments. It has five domains: Scheduling, Prenatal Care Provider, Personal Issues, and Overall assessment. In addition, there is one section titled, "technology" which addressed satisfaction in the use of equipment. Each domain section contained 3-6 questions for a total of 25 Likert questions and nine demographic questions, (see Appendix C). There is an area for written comments at the end of survey. The patient satisfaction tool was developed and validated by Bethann Pflugeisen, statistician at MultiCare Health System, Tacoma, Washington (Pflugeisen \& Mou, 2017). The patient intervention will be participation in at least one virtual visit between the $18^{\text {th }}$ and $34^{\text {th }}$ weeks of gestation. The patient had at least one traditional visit in the office setting prior to the virtual visit. After the traditional visit an educational component and return demonstration for the skills required for the virtual visit was completed and the agreement to participate in the survey was signed. The patient surveys were emailed using Qualtrics ${ }^{\mathrm{xm}}$ survey program to each subject after the completion of the virtual visit. Survey response was anonymous.

The first obstetric appointment was a traditional office visit. It was comprised of the initial pregnancy confirmation with history, physical examination and education regarding what to expect during the pregnancy. Typically, this visit is during gestational weeks 6-9. Screening for pregnancy risk factors such as 
personal history of diabetes or previous pregnancy complications begins at this visit. The next visits occur in 4-week intervals until 28 weeks of gestation, then the patient will be seen every two weeks until 36 weeks and finally every week beginning at 36 weeks until delivery. The standard assessments at each visit are: patient weight, blood pressure check, urine dipped for protein, glucose and ketones, fetal heart tone assessment via handheld doppler, assessment for bleeding or contractions and education throughout. The virtual appointments required the patient to learn how to take their own blood pressure and weight, and use a hand held doppler to assess fetal heart tones. Women of all backgrounds have consistently demonstrated the ability to competently perform these skills, not only with virtual obstetric care but through multiple studies involving Centering group prenatal care which also teaches women to participate in their own care (Cunningham et al., 2019). In the hybrid virtual model, women were seen alternately between office and virtual from about 16 weeks until approximately 34 weeks of gestation after which all visits were competed in office.

The provider evaluation also measured ordinal data utilizing a 7-point Likert scale to rank satisfaction assigning numerical values from 1-7 to correspond with: strongly agree to strongly disagree. Domains were not independently evaluated for providers. Surveys from each provider were completed after completing at least one virtual visit (See Appendix D).

\section{Setting and Sample Characteristics}

The patient and provider cohort will be a convenience sample from the obstetric group, Central Valley Women's Health Associates (CVWHA) in Fresno, California. It is a private practice model with two office locations. In addition to the local Fresno/Clovis metropolitan area, patients seeking care at this practice are 
from a large geographical distribution spreading across about five counties and may include residence in the Sierra mountain communities such as Oakhurst and the Yosemite Valley to the northeast, Los Banos to the northwest, and as far southwest as Coalinga. There is a diverse mix of patients in terms of ethnicity, religious practices, socioeconomic and professions which is reflective of the greater Fresno area. Nearly all patients have health insurance coverage including; privately funded, publicly sponsored such as MediCal and military such as TriCare and Veteran's Affairs (VA). The support staff for CVWHA are mostly bilingual in English and Spanish. The practice follows the traditional ACOG prenatal care schedule and guidelines. Generally, perinatal care is alternated between obstetrician and NPs until 36 weeks, at which time the physician sees the patients until delivery. NPs see the majority of the postpartum visits. The practice does not offer group prenatal care.

Inclusion criteria were patients who were determined to be at low risk using the ACOG guidelines, and had no positive findings from the exclusion criteria checklist (see Table 1) and then were offered the opportunity to self-select into the patient cohort.

Patient demographic information included in the evaluation were: age, income, parity, ethnicity, relationship status (partnered or not), distance to travel in miles to appointments, work outside the home and location of virtual visit.

The provider sample consisted of family nurse practitioners and Obstetricians who chose to participate in providing virtual care. As this was a pilot study, the sample size may not have statistical power but should realistically provide outcome information to direct future research. Demographics collected for the provider arm of the study included age, professional title, years of practice in current role as an advanced practice (for NP role) or as an MD. 
Table 1

Criteria Checklist

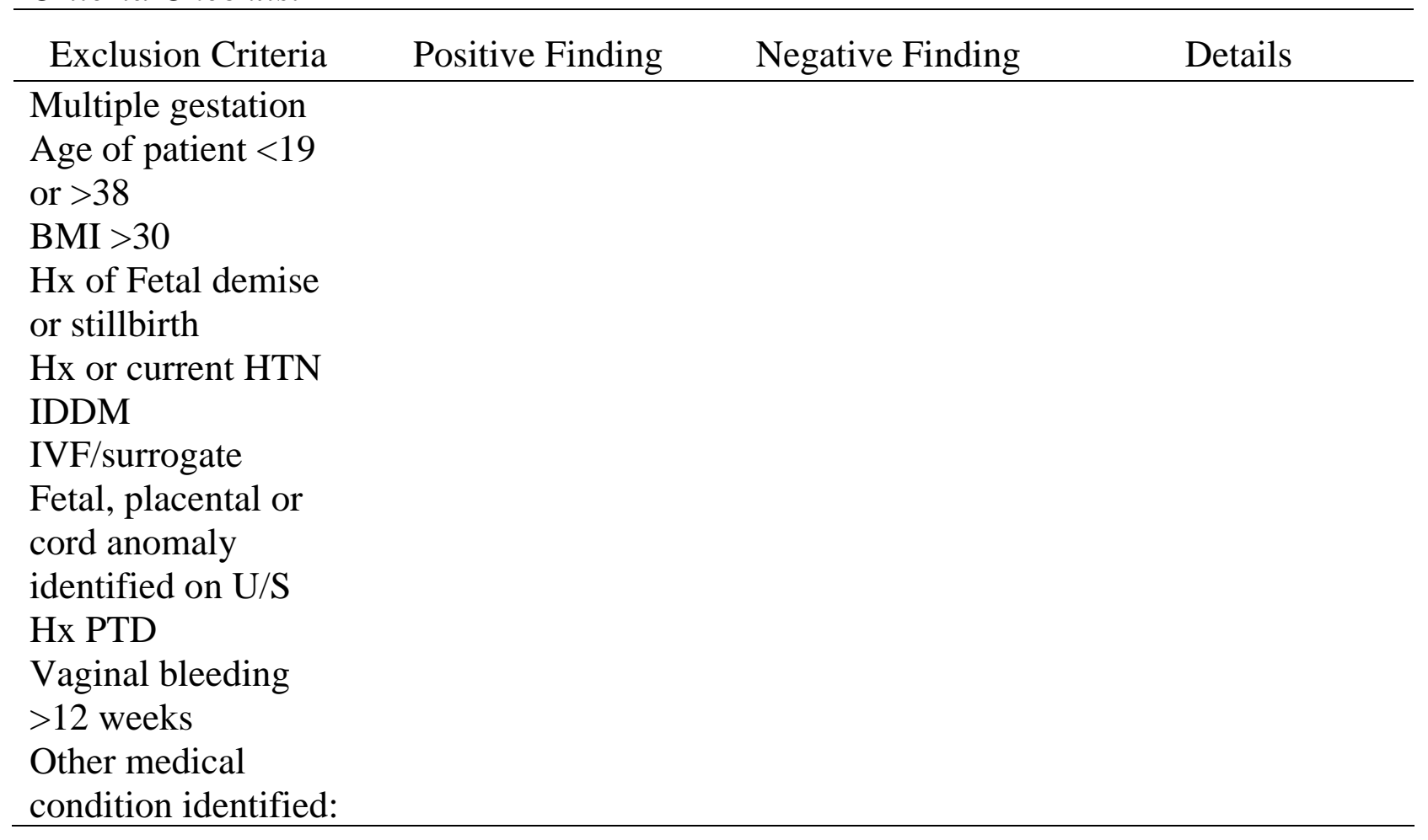

\section{Data Collection}

Data collection of the survey tools was via the e-mail survey platform Qualtrics ${ }^{\mathrm{xm}}$ program. No names or identifying information were included with the surveys. Data was collected February 23 through March 6, 2020. The patients were asked to respond after their first virtual obstetric visit. A time limit of response was 14 days. The patient survey tool has been validated and assessed for reliability. The patient survey tools were "validated for internal consistency with all Pearson correlations $\geq 0.4$ for domains and their respective questionnaire items and Cronbach's alpha $\geq 0.7$ " (Pflugeisen \& Mou, 2017). The investigator for this 
project did receive written permission to use the tool. (Appendix B). All surveys and demographic information were collected anonymously and HIPPI compliant. Participants could decline to fill out any or all questions and demographic information as listed above.

The provider questionnaire has been used widely but currently no validation of the tool has been completed. Permission to use this tool from the Southwestern Telehealth Resource Center has been granted. The tool is very similar to the patient survey. Despite the small number of providers surveyed for this project, the validity and reliability is assumed to be similar to the patient survey.

\section{Data Analysis}

Evaluation of the data used descriptive and sample T test to determine statistical significance of the satisfaction for patient experience between virtual and face to face appointments for each question within the tool and a one-way analysis of variance (ANOVA) to understand the potential influence of demographic differences. These same methods will be used to evaluate the provider satisfaction survey. (See Appendix D). 


\section{CHAPTER 4: RESULTS}

This project had two separate arms of evaluation, one arm for patients and the other for providers. Quantitative data for each arm assessed was collected independently for either the patient experience or the provider experience. Individual patient responses were compared to their own experience in participation in traditional and virtual obstetrics care. The analysis was specific to each arm however the aim of this project's investigation was to determine if the virtual experience was comparable and acceptable to the traditional office appointments for both patients and providers. The patient arm also had a question specific to the experience of the overall hybrid experience. First the demographics of each group will be described. The results for both groups will then be individually presented utilizing descriptive, paired sample T tests and one-way ANOVA as appropriate. Finally, considerations and recommendations for further investigation and research for the individual and combined groups will be discussed.

\section{Demographics}

A total of thirteen patients completed the surveys of the twenty-two distributed. The respondents are of multiple self-identified ethnicities (see Table 1). Asian and Hispanic combined representing the majority of the participants each of these groups comprising 33.33\%. The age range was from 19- 38 years of age with the majority, 53.85\% being between 32 and 39. Close to 54\% of the women lived 10 to 50 miles from the office. Nearly $85 \%$ of the participants worked outside the home with the majority, $83 \%$ having a combined household income of $\$ 30,000$ to greater than $\$ 100,000$. The large majority of the women were experiencing their first or second pregnancy. The majority of the patients 
participated in their virtual care at home, 76.92\%. Participation while on vacation represented the second most likely place where patients participated in virtual care at $15.38 \%$, while one patient was at work.

Table 2

Patient Demographics

\begin{tabular}{|c|c|c|}
\hline Ethnicity & $\%$ & $n$ \\
\hline Caucasian non-Hispanic & $8.33 \%$ & 1 \\
\hline Hispanic & $33.33 \%$ & 4 \\
\hline Asian & $33.33 \%$ & 4 \\
\hline African American & $16.67 \%$ & 2 \\
\hline other & $8.33 \%$ & 1 \\
\hline \multicolumn{3}{|l|}{ Age at time of visit } \\
\hline $19-25$ & $30.77 \%$ & 4 \\
\hline 26-31 & $15.38 \%$ & 2 \\
\hline $32-38$ & $53.85 \%$ & 7 \\
\hline \multicolumn{3}{|l|}{ Driving distance } \\
\hline$<5$ miles & $23.08 \%$ & 3 \\
\hline 5-10 miles & $23.08 \%$ & 3 \\
\hline 10-20 miles & $38.46 \%$ & 5 \\
\hline 20-50 miles & $15.38 \%$ & 2 \\
\hline > 50 miles & $0.00 \%$ & 0 \\
\hline \multicolumn{3}{|l|}{ Household Income } \\
\hline$<\$ 30,000$ & $16.67 \%$ & 2 \\
\hline$\$ 30,000-\$ 74,000$ & $41.67 \%$ & 5 \\
\hline$\$ 75,000-\$ 99,000$ & $0.00 \%$ & 0 \\
\hline$>\$ 100,000$ & $41.67 \%$ & 5 \\
\hline \multicolumn{3}{|l|}{ Pregnancy number } \\
\hline $1-2$ & $84.62 \%$ & 11 \\
\hline $3-4$ & $15.38 \%$ & 2 \\
\hline $4+$ & $0.00 \%$ & 0 \\
\hline \multicolumn{3}{|l|}{ Work outside home } \\
\hline Yes & $84.62 \%$ & 11 \\
\hline No & $15.38 \%$ & 2 \\
\hline \multicolumn{3}{|l|}{ Location during visit } \\
\hline Home & $76.92 \%$ & 10 \\
\hline Work & $7.69 \%$ & 1 \\
\hline Vacation & $15.38 \%$ & 2 \\
\hline
\end{tabular}


A total of six providers completed the surveys, three nurse practitioners and three physicians. Five of the providers responded to the work and age demographic questions. Of the five responders, Table 2 provides the results of their demographic information. Three were 40 to over 50 years of age and the other two were aged 31 to 39. Three of the providers had greater than ten years of experience in their current position, one had been in practice 5-10 years and the other had been in practice less than five years.

\section{Table 3}

Provider Demographics

\begin{tabular}{lll}
\hline Age & \% & $n$ \\
\hline $25-30$ & $0.00 \%$ & 0 \\
$31-39$ & $40.00 \%$ & 2 \\
$40-49$ & $20.00 \%$ & 1 \\
$50+$ & $40.00 \%$ & 2 \\
Years of practice & & \\
$<5$ & $20.00 \%$ & 1 \\
$5-10$ & $20.00 \%$ & 1 \\
$>10$ & $40.00 \%$ & 3 \\
\hline
\end{tabular}

\section{Survey Statistics}

The Qualtrics survey platform was used to collect both patient and provider data to evaluate participation experience for virtual and traditional office visits. Survey questions utilized Likert scales. For the patient surveys, the response options ranged from very poor to very good - which were then coded on a five point ordinal scale to quantitative data values in SPSS software to evaluate for descriptive analysis, paired sample T tests and one-way ANOVA to assess for 
significant differences between the patient experience in participation in virtual and office visits. The descriptive results indicated that the patients surveyed described their care, be it traditional or virtual as good to very good with a mean score of 4.3 or greater out of 5 for all but three of three of the thirty-five questions. Table 4 provides the three questions for which the descriptive mean results were less than 4.3 which indicated a mean that was less than "good" consistently.

\section{Table 4}

Descriptive Results for Means < 4.3

\begin{tabular}{llcc}
\hline \multicolumn{1}{c}{ Questions } & Mean & Std Deviation & Variance \\
\hline $\begin{array}{l}\text { Ease of connecting } \\
\text { to virtual visit }\end{array}$ & 4.23 & .89 & .79 \\
$\begin{array}{l}\text { Ease of accessing } \\
\text { virtual provider }\end{array}$ & 4.08 & 1.14 & 1.30 \\
$\begin{array}{l}\text { when necessary } \\
\begin{array}{l}\text { Ease of accessing } \\
\text { obstetric provider } \\
\text { when necessary }\end{array}\end{array}$ & 4.08 & 1.11 & 1.23 \\
\hline \multicolumn{1}{c}{ Note. $N=13$} & & &
\end{tabular}

The question domain of technology which only applied to virtual visits in the patient arm included four questions of which "ease of connecting to virtual visit" belongs. As the results of the three other questions in the technology domain and the twenty-nine remaining questions all indicated favorable patient experience when looking solely at descriptive analysis, no further discussion of these results will be delineated individually.

Comparison of each patient's experience between virtual and traditional visits was done using a paired sample test. Table 5 provides the results for the paired sample correlation with significance for virtual to office for patient 
experience. The comparisons are created based on the domains of scheduling, prenatal care provider, personal issues and overall assessment.

Table 5

Paired Samples Correlations for Patient Experience

\begin{tabular}{l|l|l} 
Virtual visit to office visit & Correlation & Sig \\
\hline
\end{tabular}

\begin{tabular}{|c|c|c|c|}
\hline \multicolumn{2}{|c|}{ Scheduling } & \multirow[b]{2}{*}{.609} & \multirow[b]{2}{*}{.027} \\
\hline Pair 1 & ease & & \\
\hline Pair 2 & Ontime & .194 & .524 \\
\hline Pair 3 & convenience & .044 & .885 \\
\hline \multicolumn{2}{|c|}{ Prenatal care provider } & & \multirow[b]{2}{*}{.082} \\
\hline Pair 4 & $\begin{array}{l}\text { explanation of } \\
\text { role }\end{array}$ & .500 & \\
\hline Pair 5 & friendly & .083 & .787 \\
\hline Pair 6 & $\begin{array}{l}\text { Explanation of } \\
\text { care }\end{array}$ & .395 & .182 \\
\hline Pair 7 & Provider skill & .527 & .064 \\
\hline \multicolumn{2}{|c|}{ Personal issues } & & \multirow[b]{2}{*}{.000} \\
\hline Pair 8 & $\begin{array}{l}\text { care and } \\
\text { concern }\end{array}$ & .839 & \\
\hline Pair 9 & privacy & .350 & .241 \\
\hline \multicolumn{2}{|c|}{ Overall assessments } & & \\
\hline Pair 10 & $\begin{array}{l}\text { virtual to } \\
\text { hybrid rating }\end{array}$ & .522 & .067 \\
\hline Pair 11 & $\begin{array}{l}\text { Access to } \\
\text { obstetric } \\
\text { provider }\end{array}$ & .912 & .000 \\
\hline
\end{tabular}

Note. $N=13$

The results were also mostly favorable when comparing participation experience of virtual to office visits with the exception of scheduling ease, provider care and concern and access to obstetrical providers. Table 6 provides a more detailed look at the results of these specific questions which seems to indicate that for these three specific experiences the office visit provided a better experience. 
Table 6

Paired Sample T Tests for Significant Results of Virtual to Office

\begin{tabular}{|c|c|c|c|c|}
\hline Responses & SD & $\mathrm{t}$ & correlation & sig. \\
\hline Scheduling: ease & .641 & .433 & .609 & .027 \\
\hline $\begin{array}{l}\text { Care: provider } \\
\text { concern }\end{array}$ & 408 & $<.001$ & 839 & $<.001$ \\
\hline $\begin{array}{l}\text { Personal: access } \\
\text { to provider }\end{array}$ & 494 & .562 & .912 & $<.001$ \\
\hline
\end{tabular}

When the demographic results were used to evaluate differences in patient experience, the only area that showed significance was patient income and the overall hybrid experience. Patients who earned less than $\$ 100,000.00$ per year were more likely to be more satisfied with the hybrid model (see Table 7 below). Interestingly, there were no respondents in the middle-class range of $\$ 75,000$ to $\$ 99,000$. There was one non respondent in this demographic and so the $n$ was twelve instead of thirteen.

\section{Table 7}

One-way ANOVA for Overall Patient Experience and Income

\begin{tabular}{lc|c|c|c|c|c}
\hline \multicolumn{1}{c}{ categories } & $\begin{array}{c}\text { Sum of } \\
\text { Squares }\end{array}$ & df & & $\begin{array}{c}\text { Mean } \\
\text { Square }\end{array}$ & F & Sig. \\
\hline $\begin{array}{l}\text { Between } \\
\text { Groups }\end{array}$ & 3.877 & 3 & & 1.292 & 9.692 & .004 \\
\hline $\begin{array}{l}\text { Within } \\
\text { Groups }\end{array}$ & 1.200 & 9 & & .133 & & \\
\hline Total & 5.077 & 12 & & & & \\
\hline
\end{tabular}

A comments section was available to patients. Two participants did leave comments. The results of the comments are, "Staff is always willing to listen to my concerns and help in finding solutions. I only wish they were more accessible 
by phone. I've had days where I could not get a hold of anyone in the office and this was frustrating because my work hours are the same as their business hours. Otherwise, I would still recommend this place and the providers." The other comment was, "I have been satisfied overall with providers at CVWHA, but I have been disappointed with the office staff. The staff have not been friendly/warm and the availability of appointments for me as a physician has been challenging. I feel that there are barriers to communicating directly with providers, and that the office staff do not act compassionately with the appropriate knowledge base."

The provider arm was a number of six split equally between nurse practitioners and physicians. Descriptive analysis and compared sample testing did not show any significant unfavorable leanings for either method. The demographic information was used in a one-way ANOVA for multiple questions within each domain and no p value $<0.05$ resulted. Provider comments were, "For the 'right' patient virtual is great. I don't feel you can ever entirely replace the face to face or hands on visit", "Patients verbalized the ease of the system and how they enjoyed it.", "Virtual visits provided the same interaction as face to face visits without any loss of important clinical assessments. I will continue to offer this service to my patients." 


\section{CHAPTER 5: CONCLUSIONS}

Access to perinatal care is imperative for all prenatal women. It has been shown to improve perinatal outcomes for both mothers and infants (Riley, Papile, \& Kilpatrick, 2012). Barriers to care can include transportation, the ability to find child-care, loss of work hours and distance to travel for appointments. Multiple models have demonstrated the same efficacy as the traditional office-based face to face appointments including group prenatal care (Cunningham et al., 2019) and virtual obstetric care (Pflugeisen, McCarren, Poore, Carlile, \& Schroeder, 2016). With respect to the hybrid model, the research supporting this model has been done in large institutions and health care systems. This doctoral project has been designed to evaluate patient and provider experience with a hybrid virtual obstetrics program in a private practice setting. The nature of private practice often fosters a close patient provider relationship. Incorporating a new model of practice without disrupting the established bonds of the setting while improving access to perinatal care could possibly benefit both patient and provider. Likert survey tools for both patients and providers were used to evaluate their experience in participation in an established private practice group utilizing hybrid virtual obstetrics.

The providers also responded positively to participation and a change in their venue of clinical practice. Although not documented in the research questions, all visits for this study were done in the office and not from an alternative location regardless of the type of visit. This indicates a willingness to participate in a new model of care that is patient centered in that the patients at this

phase of the implementation were able to choose their location site and the providers did not change their location. As this study was completed during the 
early phases of incorporating the hybrid virtual obstetrics model into the practice, study results regarding work flow and time use were satisfactory. The age range and years of experience varied in the provider arm indicating that practice changes are not inflexible across many professional statuses, ages or types of of experience.

\section{Study Conclusions}

Although the overall numbers for this study were low, thirteen in the patient arm and six in the provider arm, the study did demonstrate that both patients and providers found the experience to be acceptable and positive. Patients demonstrated the ability to learn new skills such as taking their own blood pressure and learning to use the fetal doppler. They also indicated that they are open to broadening their perception as to where an appointment can take place and options for their involvement. It appeared from the study question responses that the patients trusted their providers wherever the visit took place. Ethnicity and socioeconomic status of this group of patients indicated that patients of many backgrounds are accepting of alternative care settings and participation in their own care if given the opportunity. Although the majority of patients participated at home, several did participate outside the home which reveals an openness to not just the use of new technologies but also of an openness to where they feel comfortable in participating in care. Several of the patients who were at home during their visit, did have one or more children present during the virtual appointment. It is not uncommon to have children present in an office visit but the office exam rooms are set up for patient-provider interactions and not children. The virtual visits did not necessitate increased childcare needs or require children to wait in a non-child centered environment. Several of the patient's partners were 
present and participated in the use of the fetal doppler and blood pressure readings which indicates that the home environment can promote partner inclusion.

Provider participation in this study also demonstrated acceptance of virtual visits as part of a hybrid model. Again, the study was very small however there were equal numbers of nurse practitioners and physicians with a mix of experience. There was no specific question item that indicated a lack of desire to continue participation in this model.

\section{Recommendations}

This study was done in the very early stages of integrating the hybrid virtual model into the private practice studied. Repeating it at a later date with larger numbers of patients would ideally validate acceptance for both patients and providers. Additionally, more private offices in multiple sites would also enhance the level of understanding of patient and provider experience in participation. Comparing experience between sites is not as important as determining what type of practices would most provide value to the patients they serve and the providers who provide care to these patients. The providers paid for and loaned the dopplers and blood pressure cuffs to the patients in this study. Over time, they may require the patients to purchase or rent the equipment so evaluating the experience again when there is an additional cost associated with participation would be important to consider the sustainability of the model.

During the actual virtual visits, patient comments included, "After learning how to use the equipment, I know what this all means. I am going to pay closer attention to my blood pressure from now on", "I feel more accountable to my own care", "This is empowering to be able to participate in my care". These comments were not quantified or studied qualitatively for this study; however, it does 
demonstrate a willingness and aptitude for health care literacy when patients are given the chance to participate. Creating a questionnaire that evaluated a more qualitative aspect of the model would be of value to tailor the care options for the setting.

Although only one patient was at work for this study, as the option for virtual care expands and more patients participate, having the ability to compare the setting where the virtual visit took place would be important.

As this project is wrapping up, the nation is in a time of distress from the COVID-19 pandemic. Multiple offices have contacted the investigator and the office where this study took place to try to create a hybrid obstetric program of their own. This illustrates a high degree of promise for future opportunities for increased research in the very near future. 
REFERENCES 


\section{REFERENCES}

American College of Obstetricians and Gynecologists. (2012). Facts are important prenatal care is important to healthy pregnancies. Retrieved from https://www.acog.org/-/media/Departments/Government-Relations-andOutreach/20120221FactsareImportant.pdf?dmc=1\&ts=20190416T00263641 83

Baker-Ericzén, M. J., Dueñas, C., Landsverk, J. A., Connelly, C. D., Hazen, A. L., \& Horwitz, S. M. (2012). A collaborative care telemedicine intervention to overcome treatment barriers for Latina women with depression during the perinatal period. Families, Systems \& Health: The Journal of Collaborative Family HealthCare, 30(3), 224-240. doi:10.1037/a0028750

Bertalanffy, L. v. (1968). General systems theory: Foundations, development, applications. New York, NY: George Braziller.

Bronstein, J. M., Ounpraseuth, S., Jonkman, J., Fletcher, D., Nugent, R. R., McGhee, J., \& Lowery, C. L. (2012). Use of specialty ob consults during high-risk pregnancies in a medicaid-covered population: Initial impact of the Arkansas ANGELS intervention. Medical Care Research \& Review, 69(6), 699-720. doi:10.1177/1077558712458157

Brown Cooper, S. (2015). Opinion leaders' perspective of the benefits and barriers in telemedicine: A grounded theory study of telehealth in the midwest. Quarterly Review of Distance Education, 16(1), 25-53. 
California Department of Public Health. (2017). Local maternal, child and adolescent health (mcah) programs: Fresno county. Retrieved from https://www.cdph.ca.gov/Programs/CFH/DMCAH/LocalMCAH/Pages/Coun ty-Profiles.aspx

California Department of Public Health. (2019). Regional perinatal programs of California [website]. Retrieved from https://www.cdph.ca.gov/Programs/CFH/DMCAH/RPPC/Pages/default.aspx

Cunningham, S. D., Lewis, J. B., Thomas, J. L., Grilo, S. A., \& Ickovics, J. R. (2017). Expect with me: Development and evaluation design for an innovative model of group prenatal care to improve perinatal outcomes. BMC Pregnancy \& Childbirth, 17, 1-13. doi:10.1186/s12884-017-1327-3

Cunningham, S. D., Lewis, J. B., Shebl, F. M., Boyd, L. M., Robinson, M. A., Grilo, S. A., Ickovics, J. R. (2019). Group prenatal care reduces risk of preterm birth and low birth weight: A matched cohort study. Journal of Women's Health, 28(1), 17-22. doi:10.1089/jwh.2017.6817

Houser, B., \& Player, K. (2007). Pivotal moments in nursing: Leaders who changed the path of a profession. Indianapolis, IN: Sigma Theta Tau International.

.King, I. M. (1981). A theory for nursing: Systems, concepts, process. New York, NY: John Wiley.

King, I. M. (1991). Nursing theory 25 years later. Nursing Science Quarterly, 4, 94-95. 
Lenz, E. R. (1998). Beneath the surface. The role of middle-range theory for nursing research and practice: Part 2. Nursing practice. Nursing Leadership Forum, 3(2), 62-66.

Pflugeisen, B. M., McCarren, C., Poore, S., Carlile, M., \& Schroeder, R. (2016). Virtual visits: Managing prenatal care with modern technology. American Journal Maternal Child Nursing 41(1), 24-30.

Pflugeisen, B. M., \& Mou, J. (2017). Patient satisfaction with virtual obstetric care. Maternal \& Child Health Journal, 21(7), 1544-1551. doi:10.1007/s10995-017-2284-1

Phillippi, J. C. (2009). Women's perceptions of access to prenatal care in the united states: A literature review. Journal of Midwifery \& Women's Health, 54(3), 219-225. doi:10.1016/j.jmwh.2009.01.002

Riley, L., Papile, L.-A., \& Kilpatrick, S. J. (2012). Guidelines for perinatal care. Chicago, IL : American Academy of Pediatrics.

Rogers, E. M. (2003). Diffusion of innovations (5 ed.). New York, NY: Free Press.

Roth, M. (2018). Telehealth: No longer optional. Health Leaders Magazine, 21(6), 20-28.

Rutledge, C. M., Haney, T., Bordelon, M., Renaud, M., \& Fowler, C. (2014). Telehealth: Preparing advanced practice nurses to address healthcare needs in rural and underserved populations. International Journal of Nursing Education Scholarship, 11,(1-9). 
Shapiro-Mendoza, C. K., Barfield, W. D., Henderson, Z., James, A., Howse, J. L., Iskander, J., \& Thorpe, P. G. (2016). CDC grand rounds: Public health strategies to prevent preterm birth. Morbidity \& Mortality Weekly Report, 65(32), 826-830. doi:10.15585/mmwr.mm6532a4

Sieloff Evans, C. (1991). Imogene king: A conceptual framework for nursing. Newbury Park, CA: Sage.

U.S. Department of Health and Human Services. (2010). 2020 leading health indicators. Retrieved from https://www.healthypeople.gov/2020/topicsobjectives/topic/maternal-infant-and-child-health/objectives\#4825.

Whetsell, M. V., Gonzalez, Yolanda M., and Moreno-Fergusson, Maria Elisa. (2018). Models and theories focused on a systems approach In J. B. Butts and Karen Rich (Ed.), Philosophies and theories for advanced nursing practice (3rd ed., pp. 455-484). Burlington, MA: Jones \& Bartlett Learning.

Wong, P. C., \& Kitsantas, P. (2019). A review of maternal mortality and quality of care in the USA. Journal of Maternal-Fetal \& Neonatal Medicine, 32(2), 111. doi:10.1080/14767058.2019.1571032 
APPENDICES 
APPENDIX A: MULTICARE PERMISSION TO USE SURVEY 
Virtual Visits

12 weeks: with MD

16 weeks: with NP

24 weeks with NP

30 weeks with NP

34 with MD

1-2 weeks postpartum

With NP (in office if post c/s)

Additional appointments as needed

\section{Doctor's Office Visits}

First appointment: History and physical exam with NP

20 weeks: MD visit ultrasound review

28 weeks: MD visit

32 Weeks MD visit

36, 37, 38, 39, 40 weeks with MD

Postpartum exam, six weeks after delivery with NP or MD

Additional appointments as needed

0 
APPENDIX B: PERMISSION TO USE SURVEY 
Gretchen Nelson <gnelson@mail.fresnostate.edu>

Mon, Mar 4, 2019 at

To: bethann.pflugeisen@multicare.org

12:08 PM

Hello Bethann Pflugeisen,

I recently read your research article on patient satisfaction with virtual obstetric in the journal, Maternal Child Health (2017) and would like the opportunity to speak with you or at least correspond via e-mail regarding your study to gain a better understanding of your setting so that hopefully I can gain a better insight into the use of telehealth, virtual-care, in obstetrics. I am a doctoral student (DNP) in Central California, wanting incorporate virtual-care in the OB practice in which I work as part of my doctoral research. I also would like permission to use your satisfaction tool if possible. We current don't provide any virtual-care in our practice so any information would be helpful.

I look forward to hearing from you,

Gretchen A Nelson FNP-c

On Mon, Apr 22, 2019 at 11:04 AM Bethann Pflugeisen <bpflugeisen@multicare.org> wrote:

$\mathrm{Hi}$ Gretchen,

What are the modifications you're planning to make? I think it would be fine for you to use the tool and appreciate you acknowledging us.

Bethann

Bethann Mangel Pflugeisen, MS, MEd | Research Scientist

MultiCare Institute for Research and Innovation

Cell: 206.799.9067 | Fax: 253.403.2391

Address: 314 Martin Luther King Jr. Way, Suite 402, Tacoma, WA 98405

Gretchen Nelson <gnelson@mail.fresnostate.edu>

Mon, Apr 22, 2019 at 1:06

To: Bethann Pflugeisen <bpflugeisen@multicare.org>

Bethann,

Thanks for the quick response. I need to run it by my adviser and chair, but in place of provider or obstetrician, such as "ease of accessing obstetrician" I would like to use "obstetric provider". In the instructions to patients indicate that obstetric provider could be an OB, NP, CNMW. The group I work with is private practice and I think we will schedule some of the virtual visits with not just an NP.

Also, do you have a Word copy of the document that you would be willing to share? I only have the pdf that is in the article. If you don't, no worries.

Gretchen

Bethann Pflugeisen <bpflugeisen@multicare.org>

Mon, Apr 22, 2019 at 6:56

To: Gretchen Nelson <gnelson@mail.fresnostate.edu>

Hi Gretchen,

Those changes certainly do sound mild, and totally reasonable. Attached are Word copies of the instrument. I look forward to seeing your results! 
Bethann Mangel Pflugeisen, MS, MEd | Research Scientist MultiCare Institute for Research and Innovation

Cell: 206.799.9067 | Fax: 253.403.2391

Address: 314 Martin Luther King Jr. Way, Suite 402, Tacoma, WA 98405 
APPENDIX C: PATIENT SURVEY 
Q1 Thank you for completing this survey. If a question does not apply to you or you do not feel comfortable answering it, please skip it. It should take 5-10 minutes to complete. You may stop and return at a later time if needed.

Q2 Scheduling: for your virtual visit

\begin{tabular}{|c|c|c|c|c|c|}
\hline & $\begin{array}{l}\text { Very Poor } \\
\text { (1) }\end{array}$ & Poor (2) & Fair (3) & Good (4) & $\begin{array}{l}\text { Very Good } \\
\text { (5) }\end{array}$ \\
\hline $\begin{array}{c}\text { Ease of } \\
\text { scheduling } \\
\text { your virtual } \\
\text { visit (1) }\end{array}$ & $\bigcirc$ & $\bigcirc$ & $\bigcirc$ & $\bigcirc$ & $\bigcirc$ \\
\hline $\begin{array}{l}\text { Frequency } \\
\text { which your } \\
\text { virtual visit } \\
\text { started on } \\
\text { time (2) }\end{array}$ & $\bigcirc$ & $\bigcirc$ & $\bigcirc$ & $\bigcirc$ & O \\
\hline $\begin{array}{l}\text { Convenience } \\
\text { of your } \\
\text { virtual visit } \\
\text { times and } \\
\text { dates (3) }\end{array}$ & $\bigcirc$ & $\bigcirc$ & $\bigcirc$ & $\bigcirc$ & $\bigcirc$ \\
\hline \multicolumn{6}{|c|}{ Q3 Scheduling: for your office visit at CVWHA } \\
\hline & $\begin{array}{l}\text { Very Poor } \\
\text { (39) }\end{array}$ & Poor (41) & Fair (42) & Good (43) & $\begin{array}{l}\text { Very Good } \\
\text { (44) }\end{array}$ \\
\hline $\begin{array}{c}\text { Ease of } \\
\text { scheduling } \\
\text { your office } \\
\text { visit (1) }\end{array}$ & $\bigcirc$ & $\bigcirc$ & $\bigcirc$ & $\bigcirc$ & $\bigcirc$ \\
\hline $\begin{array}{l}\text { Frequency } \\
\text { which your } \\
\text { officevisit } \\
\text { started on } \\
\text { time (2) }\end{array}$ & $\bigcirc$ & $\bigcirc$ & $\bigcirc$ & $\bigcirc$ & $\bigcirc$ \\
\hline $\begin{array}{l}\text { Convenience } \\
\text { (3) }\end{array}$ & $\bigcirc$ & 0 & $\bigcirc$ & $\bigcirc$ & ○ \\
\hline
\end{tabular}




\begin{tabular}{c|ccc}
$\begin{array}{c}\text { Q4 } \\
\text { Technology }\end{array}$ & $\begin{array}{c}\text { Very Poor } \\
(1)\end{array}$ & Poor (2) $\quad$ Fair (3) Good (4) & $\begin{array}{c}\text { Very Good } \\
\text { (5) }\end{array}$ \\
\hline $\begin{array}{c}\text { Ease of } \\
\text { connecting } \\
\text { for the virtual } \\
\text { visit (1) }\end{array}$ \\
$\begin{array}{c}\text { Quality of } \\
\text { connection } \\
\text { during the } \\
\text { virtual visit } \\
\text { (2) }\end{array}$ \\
$\begin{array}{c}\text { Ease of using } \\
\text { the blood } \\
\text { pressure } \\
\text { monitor (3) }\end{array}$ \\
$\begin{array}{c}\text { Ease of using } \\
\text { the Doppler } \\
\text { to hear the } \\
\text { baby's heart } \\
\text { tones (4) }\end{array}$
\end{tabular}




\begin{tabular}{|c|c|c|c|c|c|}
\hline $\begin{array}{l}\text { Q5 Prenatal Care } \\
\text { Provider for your } \\
\text { Virtual Visit }\end{array}$ & $\begin{array}{l}\text { Very Poor } \\
\text { (1) }\end{array}$ & Poor (2) & Fair (3) & Good (4) & $\begin{array}{l}\text { Very Good } \\
\text { (5) }\end{array}$ \\
\hline $\begin{array}{l}\text { How well the virtual } \\
\text { visit provider } \\
\text { explained their role } \\
\text { in your care (1) }\end{array}$ & $\bigcirc$ & $\bigcirc$ & $\bigcirc$ & $\bigcirc$ & $\bigcirc$ \\
\hline $\begin{array}{c}\text { Friendliness/courtesy } \\
\text { of the virtual visit } \\
\text { provider (2) }\end{array}$ & $\bigcirc$ & $\bigcirc$ & $\bigcirc$ & ○ & $\bigcirc$ \\
\hline $\begin{array}{l}\text { Explanations about } \\
\text { how to use the blood } \\
\text { pressure cuff and } \\
\text { Doppler (3) }\end{array}$ & $\bigcirc$ & $\bigcirc$ & $\bigcirc$ & $\bigcirc$ & O \\
\hline $\begin{array}{l}\text { Skill and knowledge } \\
\text { of the virtual visit } \\
\text { provider (4) }\end{array}$ & $\bigcirc$ & ○ & $\bigcirc$ & $\bigcirc$ & $\bigcirc$ \\
\hline $\begin{array}{l}\text { Degree to which the } \\
\text { virtu visit provider } \\
\text { took the time to } \\
\text { listen to you (5) }\end{array}$ & $\bigcirc$ & $\bigcirc$ & $\bigcirc$ & $\bigcirc$ & $\bigcirc$ \\
\hline $\begin{array}{l}\text { Virtual visit } \\
\text { provider's concern } \\
\text { for your questions } \\
\text { and worries (6) }\end{array}$ & $\bigcirc$ & $\bigcirc$ & $\bigcirc$ & $\bigcirc$ & $\bigcirc$ \\
\hline \multicolumn{6}{|c|}{ Q6 Prenatal Care Provider at during your office visit } \\
\hline & & $r(2)$ & Fair (3) & Good (4) & $\begin{array}{l}\text { Very Good } \\
\text { (5) }\end{array}$ \\
\hline
\end{tabular}

\section{How well did your care provider explained their role in your care (1) \\ Friendliness of your prenatal care provider (2)}




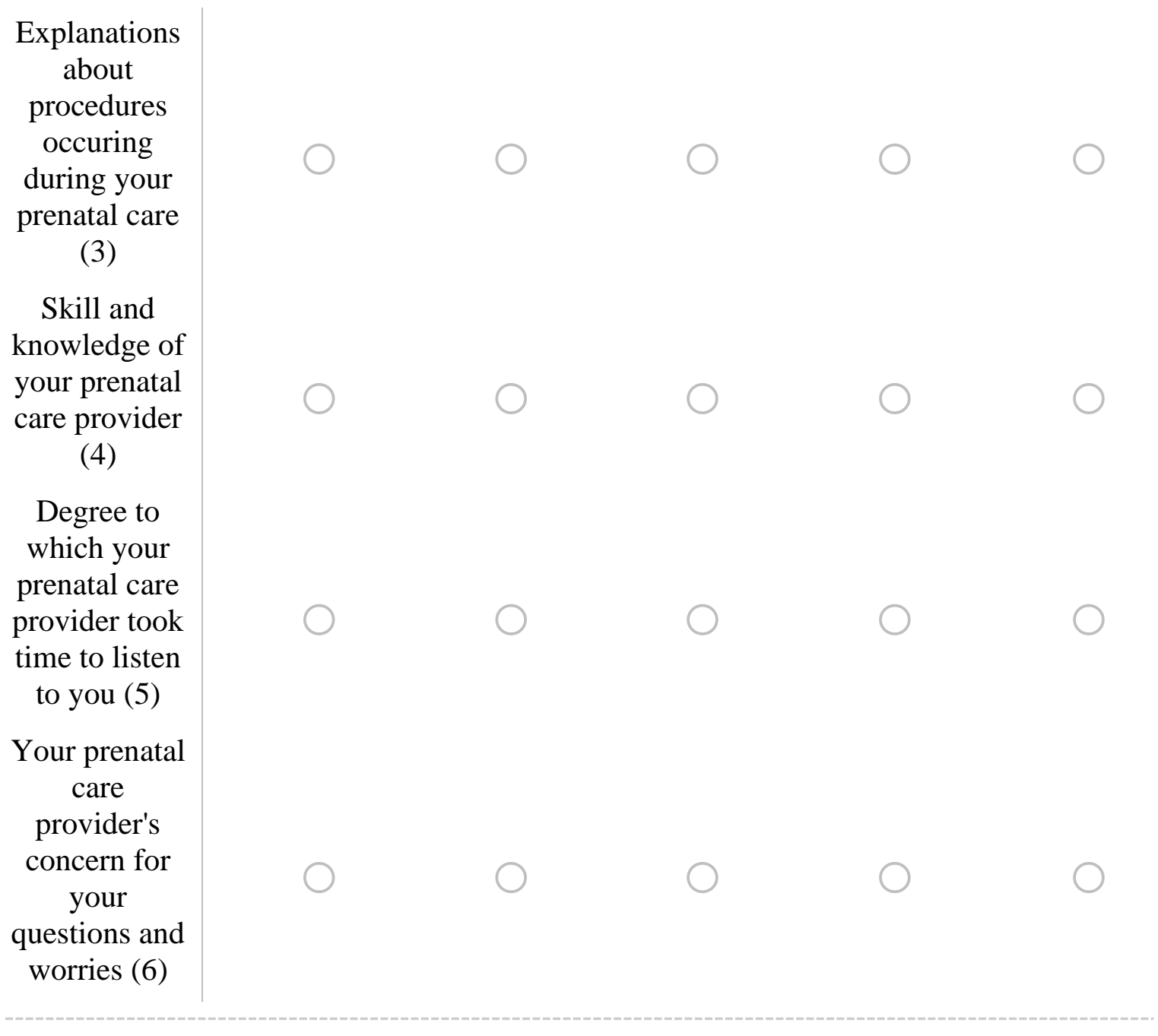




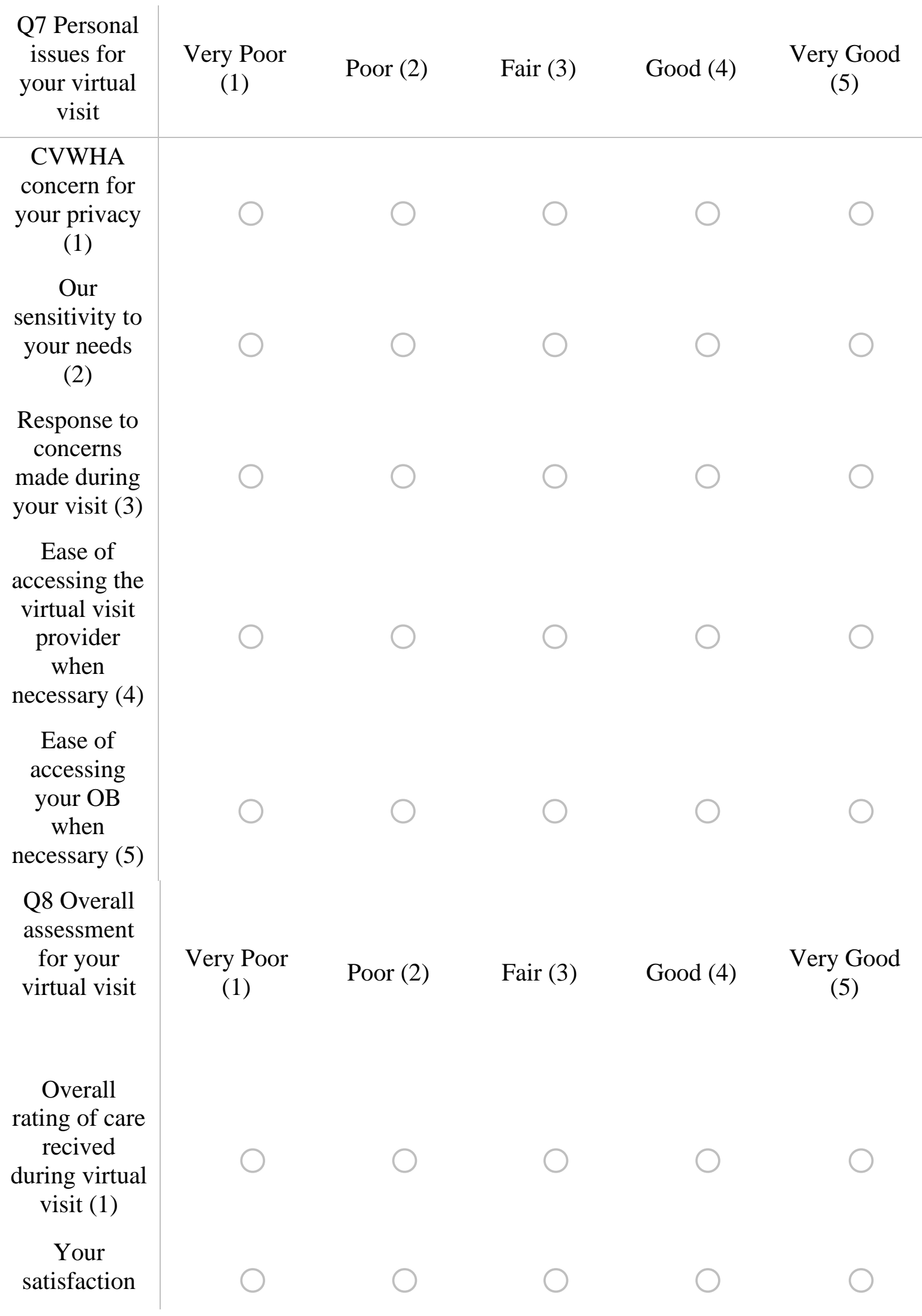




\section{with a mix of virtual and in-person visits (2) \\ Likelihood that you would recommend virtual visits to others (3) \\ Likelihood that you will continue to seek care with CVWHA (4)}

Q9 Overall Assessment for your office visits

Very Poor

(1)

Overall
rating of care
recived
during your
prenatal care
visits (1)
Your
satisfaction
with your
prenatal care
visits (2)
Likelihood
that you
would
recommend
your prenatal
care provider
to others (3)
Likelihood
that you will
continue to
seek care

Poor (3)
Fair (4)

Good (5)
Very Good

(6) 
from

CVWHA (4)

Q10 Comments:

Q11 Pregnancy information: Please indicate for which pregnancy you participated in virtual care:

\section{$1-2(1)$ \\ 3-4 (2) \\ $4+(3)$}

Q12 Where were you during your virtual visit

Home (1)

Work (2)

vacation (3)

other (4)

Q13 Are you working outside of home?

Yes (1)

No (2) 
Q14 Are you in a married/partnered relationship?

Yes (1)

No (2)

Q15 Have you experienced a pregnancy loss in the past (miscarriage/stillborn/ectopic) ?

Yes (1)

No (2)

Q16 Age at the time of your virtual visit

$19-25$ (4)

26-31 (5)

32-39 (6)

Q17 To what ethnic group(s) do you identify?

Caucasian non hispanic (4)

hispanic (5)

Asian (6)

African American (7)

other (8) 
Q18 Approximately how far is your home, in one direction, from your OB's office?

$<5$ miles (1)

5-10 miles (2)

10-20 miles (3)

20-50 miles (4)

$>50$ miles (5)

Q19 Combined annual income level for your home:

(1)

$\$ 30,000-\$ 74,000$

$\$ 75,000-\$ 99,000$

$>>100,000$ (4) 
APPENDIX D: PROVIDER SURVEY 
Q1 Instructions: Please rate the following on a scale of strongly disagree, disagree, somewhat disagree, somewhat agree, agree, and strongly agree. Please only answer what you feel comfortable in answering. You can skip any question. It should take about 5 minutes to complete.

Q2 The provider experience of the quality of the traditional visit.

\begin{tabular}{ccccccc} 
strongl & \multicolumn{9}{c}{ Somewh } & $\begin{array}{c}\text { Neither } \\
\text { agree }\end{array}$ & Somewh & Agre & Strongl \\
y & Disagre & at & nor & at agree & e (6) & y agree \\
disagre & e (2) & disagree & disagre & (5) & & (7) \\
e (1) & & (3) & e (4) & & &
\end{tabular}

The

quality of

the

traditional

visit was

acceptabl

e (1)

Accuracy in FHT

assessme

nt was

better in

office (2)

The

ability to

touch the

patient

improved

the visit

experienc

e (3) 
The clinical exam provided better quality information (4) I am confident that the experience provided accurate assessment data (5)

The environment distracted me from the patient provider experience (6)

There was no technical difficulties during the office visit (7) Workflow was better with the traditional visit (8)

The traditional visit takes longer than virtual visit (9) The traditional visits improve clinical efficacy (10) 


My
communication
with the patient
was improved
compared to
the virtual visit
(11)
I was better
able to observe
details of the
patient's facial
expression and
body
movements
that are
important in
connecting
with her (12)
The doctor-
patient rapport
was
unimpaired
during the
traditional visit
(13)
I would have
preferred to see
this patient
virtually (14)

Q2 Provider satisfaction experience of virtual visit

\begin{tabular}{ccccccc} 
strongl & \multicolumn{9}{c}{$\begin{array}{c}\text { Somewh } \\
\text { y }\end{array}$} & $\begin{array}{c}\text { Neithe } \\
\text { r agree }\end{array}$ & $\begin{array}{c}\text { Somewh } \\
\text { Disagre }\end{array}$ & at & Agre & Strongl \\
disagre & e (2) & disagree & nor & agree & e (6) & y agree \\
e (1) & & $(3)$ & $\begin{array}{c}\text { disagre } \\
\text { e (4) }\end{array}$ & (5) & & (7)
\end{tabular}

The quality of the visual 


was
acceptable
(1)
The quality
of the audio
was
accpetable
(2)
I could
accurately
assess
audible FHT
if needed (3)
The inability
to touch the
patient
impaired the
visit
experience
(4)
The virtual
clinical exam
provided
sufficient
information
(5)
I am
confident
that the
experience
provided
accurate
assessment
data (6)
The
technology
distracted me
a


from the
patient
provider
experinece

(7)

Technical difficulties made this process too timeconsuming (8)

Overall, the system was accessible and easy to use (9)

The virtual visit takes longer than face to face (10)

Telemedicine improves clinical efficency

(11)

My

communicati on with the patient was unimpaired by telemedicine (12)

I would have prefered to 
see the

patient in the

office. (13)

Q5 Comments:

Q7 Type of provider:

MD, OB/GYN (1)

NP (2)

Q8 Years of practice in current profession

$<5$ years (1)

5-10 years (2)

$>10$ years $(3)$

Q9 Current age in years:

25-30 (1)

31-39 (2)

$40-49(3)$

$50+(4)$ 